Foro Interno. Anuario de Teoría Política

ISSN: 1578-4576

http://dx.doi.org/10.5209/FOIN.57206

\title{
"Die Arbeit als eine Pest geflohen wird": La crítica al trabajo asalariado en los Manuskripte de 1844 de Karl Marx
}

Cristopher Morales Bonilla ${ }^{2}$

Recibido: 29 de diciembre de 2015 / Aceptado: 16 de diciembre de 2016

Resumen: Los Ökonomisch-philosophische Manuskripte de 1844 de Marx establecen las bases del proyecto marxista de superación del capitalismo. Para ello, desarrolla una crítica al trabajo asalariado desde el concepto de alienación procedente de la dialéctica hegeliana y de la crítica de Feuerbach a la religión. Este análisis le sirve para establecer otros conceptos como los de una alteridad materialista o la reducción a la animalidad, desde los cuales sería posible construir otro marxismo alternativo al de Das Kapital.

Palabras clave: Alienación; trabajo; alteridad; mundo común.

\section{[en] "Die Arbeit als eine Pest geflohen wird"3: The Critique of Wage Labor in Karl Marx's Manuskripte of 1844}

Abstract: Marx's Ökonomisch-philosophische Manuskripte of 1844 established the basis for the Marxist project to overcome capitalism. For this purpose, he developed a critique of wage-labor from the dual perspectives of a Hegelian dialectic and a Feuerbachian critique of religion. This analysis served to establish other concepts such as a materialist alterity and the reduction of man to animality, from which one could build an alternative Marxism, different from that which was evident in Das Kapital.

Keywords: Alienation; labor; alterity; common world.

Cómo citar: Cristopher Morales Bonilla, “'Die Arbeit als eine Pest geflohen wird': La crítica al trabajo asalariado en los Manuskripte de 1844 de Karl Marx”: Foro Interno. Anuario de Teoría Política, vol. 17 (2017), pp. 73-96.

Le travailleur ne se produit pas lui-même, il produit une puissance indépendante. Le succès de cette production, son abondance, revient vers le producteur comme abondance de la dépossession.

Guy Debord ${ }^{4}$

\footnotetext{
"Se huye del trabajo como de la peste". Véase nota al pie n. 23.

2 Investigador independiente

E-mail: cmoralbon@gmail.com

3 "People avoid work like the plague".

4 Guy Debord, Euvres, ed. de Jean-Louis Rançon, Gallimard, Paris, 2006, p. 774.
} 


\section{Introducción}

En la historia del marxismo del siglo veinte la crítica al trabajo asalariado fue una de las primeras víctimas de la conversión del materialismo histórico de Karl Marx (18181883) en el materialismo dialéctico de Iósif Stalin (1878-1953). Fruto de un productivismo radical, la necesidad de superación del trabajo asalariado en las condiciones del modo de producción capitalista quedó olvidada bajo la idea de que la instauración de unas formas de trabajo socialistas eliminaría los elementos de alienación de aquella.

En el contexto de nuestro comienzo de siglo veintiuno puede parecer todo un anacronismo centrar el objeto de estudio en los análisis de Marx de hace más de siglo y medio, es decir, hacer una especie de salto por detrás de todas las corrientes en las que se ha desarrollado el marxismo. No hay que olvidar que después de las criminales experiencias del "socialismo real", la obra de Marx ha sido interpretada desde dos líneas de fuerza diferentes: por un lado, su completo rechazo por ser considerada como "filosofía superada"; por otro, la reivindicación de un cierto Marx que, pese a la victoria del liberalismo y de la democracia representativa, se mantiene como el auténtico profeta inmortal de la transformación social cuyo diagnóstico ha de ser necesariamente definitivo.

Sin embargo, después de las numerosas crisis, reformulaciones y derrotas que ha sufrido el marxismo a lo largo de toda su historia, parece necesario traer al presente aquellos conceptos que, por distintas razones, fueron dejados de lado en la construcción de un materialismo histórico monolítico, para poder comprobar si, todavía, queda algo por rescatar de Marx antes de atrevernos a producir nuevos conceptos para nuevas realidades sociales e históricas.

La crítica al trabajo asalariado parece uno de estos conceptos. De un modo general, podría decirse que hay en la obra de Marx dos desarrollos diferentes de este tema: el primero, todavía dentro de la filosofía posthegeliana, está desarrollado en los Manuskripte de $1844^{6}$. El segundo, ya en el marco de la crítica de la economía política, es el que se despliega en los Grundrisse $e^{7}$

5 El mejor ejemplo de estas corrientes son las que encuadran a Marx dentro de la cuestión del final de la Historia. Sobre este tema es de destacar el ya clásico libro de Fukuyama. Cf. Francis Fukuyama, The End of History and the Last Man, Macmillan, New York, 1992.

6 Sobre el contexto en el que se redactaron, véase la Introducción de Francisco Rubio Llorente en Karl Marx, Manuscritos: economía y filosofia, trad. de Francisco Rubio Llorente, Alianza, Madrid, 1979, pp. 12-13. Para entender las condiciones en las que fueron escritos los Manuskripte, véase Jorge Veraza, Los Manuscritos de 1844. Un discurso integral, Ítaca, Ciudad de México, 2011, pp. 16-20, en especial en relación a la cuestión del Vorrede. Sobre la ordenación de los tres manuscritos que conforman el texto y su construcción, véase ibid., pp. 21-27; Margaret A. Fay, The 1844 Economic and Philosophic Manuscripts of Karl Marx: A Critical Commentary and Interpretation, Tesis Doctoral inédita, University of California, Berkeley, 1980, en el que se explica la diferencia entre el modo que fueron escritos y el modo en que fueron editados en el MEGA (Proyecto Marx-Engels-Gesamtausgabe); sobre el modo en que fueron redactados, véase Veraza, Los Manuscritos de 1844, pp. 28-34; en relación a los aspectos filológicos más importantes de los Manuskripte, además de una lista con todos los cuadernos que conforman la base del texto, véase Marcello Musto, "Marx en París: Los Manuscritos económico-filosóficos de 1844", en Marcello Musto (coord.), Tras las huellas de un fantasma. La actualidad de Marx, Siglo XXI, Ciudad de México, 2011, pp. 116-132. Incluso, caben interpretaciones que los sitúan como textos cercanos a la vanguardia artística en relación al modo en que fueron escritos. Sobre una interpretación semejante, véase Gary Tedman, "Marx’s 1844 Manuscripts as a Work of Art: A Hypertextual Reinterpretation”: Rethinking Marxism, vol. 16, n. ${ }^{\circ} 4$ (2004), pp. 427-441.

7 Sobre la crítica al trabajo asalariado en los Grundrisse, véase Karl Marx y Friedrich Engels, Werke (MEW), vol. 42, Dietz Verlag, Berlin, 1983. Para un estudio de la influencia de estos textos en el conjunto del marxismo contemporáneo, véase Antonio Negri, Marx más allá de Marx. Cuaderno de trabajo sobre los Grundrisse, trad. de Carlos Prieto del Campo, Akal, Madrid, 2001. 
Pese a que son dos formulaciones diferentes de un mismo problema, lo que se desarrollará aquí será la primera de estas versiones. Por una razón principal: sin la fundamentación de los Manuskripte no podría haber existido la de los Grundrisse. Pese a lo que ciertas corrientes marxistas han intentado demostrar una y otra vez a lo largo de décadas 8 , el llamado "primer Marx" establece las bases de la crítica de la economía política, auténtico campo de batalla de la lucha por la destrucción del capitalismo. Es cierto que estas bases no son estrictamente económicas. Sin embargo, como se verá, la heteronomía en la fundamentación fue, o pudo ser y no llegó a serlo, el elemento clave para librar al marxismo de la caída inevitable en el economicismo?

Dentro del conjunto de los conceptos abiertos y poco desarrollados por Marx, la crítica al trabajo asalariado tiene una importancia decisiva por ser transversal tanto a la crítica moderna y contemporánea del capitalismo como al marxismo burocratizado. Ambos modelos teóricos, por diferentes razones, no han conseguido organizar el trabajo de una forma que supere los elementos de alienación que Marx identifica en los Manuskripte. Este concepto, junto con otros, hace que, todavía hoy, podamos usar a Marx de una forma crítica incluso contra ese constructo político-filosófico llamado marxismo.

La crítica al trabajo asalariado de los Manuskripte se despliega a través del desarrollo de otro concepto igualmente olvidado en el marxismo histórico: el concepto de alienación (Entfremdung/Entäusserung $)^{10}$. El campo de análisis de Marx en cuanto al extrañamiento del trabajador con respecto a su mundo es el modo en el que este garantiza su vida, el medio en el que interactúa con la naturaleza para poder asegurar su subsistencia: el trabajo. Desde su esencia como ser que trabaja, la actividad asalariada aparecería como la desposesión en cuanto individuo de aquello que crea, una relación con la naturaleza que debería servirle para su propia liberación. Sin embargo, ocurre justo lo contrario: en la esfera de la actividad asalariada, la subjetividad, en cuanto trabajador que produce, se relaciona con la naturaleza a través de los medios de producción, convirtiéndose el trabajador en un extraño para sí mismo.

Esta desposesión del trabajo de todo lo que conlleva su actividad tendrá cuatro aspectos: a) enajenación en relación al producto del trabajo; b) enajenación en el acto mismo de la producción; c) enajenación con respecto al modo genérico de la vida universal; d) enajenación con respecto al otro. A partir de la exposición de cada

8 El momento clave en la historiografía marxista en relación a los Manuskripte se encuentra en la obra de Louis Althusser (1918-1990) Cf. Louis Althusser, y Etienne Balibar, Pour Marx, La Découverte, Paris, 1986. Por su parte, en el mundo soviético se recibieron, al principio, como una gran contribución de Marx a las cuestiones económicas. Sin embargo, a partir de la edición completa en ruso (1956) empezó a desarrollarse la conciencia de su peligrosidad para alimentar ciertos "revisionismos" del momento. Sobre la recepción de los Manuskripte en la URSS, cf. Murray Yanowitch, "Alienation and the Young Marx in Soviet Thought": Slavic Review, vol. 26, n. ${ }^{\circ} 1$ (1967), pp. 29-53.

9 Para entender la relación del primer Marx con la crítica de la economía política véase Marx, Manuscritos: economía y filosofía, pp. 16-17. El uso que se hará de textos previos a la redacción de Das Kapital tratará de demostrar una de las tesis de fondo de este artículo: no existe una división radical entre el Marx denominado "humanista" y el Marx de la crítica de la economía política. El proceso que se puede observar es el progresivo cambio de los conceptos de la filosofía alemana posthegeliana a las categorías de la economía política (Adam Smith, Ricardo, etc).

10 Aunque, como veremos, en las citas reproducidas Marx usa este término indistintamente, existe una pequeña diferencia entre las dos palabras. En alemán, Entfremdung se relaciona con lo extraño gracias a la raíz "fremd", que significa "extraño, extranjero, forastero". Por su parte, Entäusserung remite a la desposesión. "Sich etwas entäussern" significa "desprenderse de algo". Por lo tanto, "alienación" remite tanto a un proceso de extrañamiento de sí como a una desposesión de lo propio. Para una aclaración del concepto en los Manuskripte, véase la nota del traductor en Marx, Manuscritos: economía y filosofía, pp. 42-43. 
elemento, se investigarán sus consecuencias y sus críticas más importantes para el pensamiento emancipador contemporáneo, más concretamente para la crisis actual del marxismo como crítica de la transformación social, todo bajo la hipótesis general de la posibilidad de articulación de un pensamiento post-marxista ${ }^{11}$.

\section{Enajenación en relación al producto del trabajo}

\subsection{Dialéctica del trabajo asalariado}

El primer modo en el que Marx expone la crítica del trabajo asalariado a través del concepto de "alienación" es en relación al objeto del trabajo. Aunque el trabajador fabrica mercancías, estas se le aparecen como objetos extraños y hostiles. La alienación en este primer sentido consiste en que el mundo creado por el proletariado se convierte en independiente y hostil a ellos. El resultado de su trabajo se les aparece como extraño, como algo que no les pertenece. Aparecen aquí tanto el extrañamiento como la desposesión:

El objeto que el trabajo produce, su producto, se enfrenta a él como un ser extraño, como un poder independiente del productor. El producto del trabajo es el trabajo que se ha fijado en un objeto, que se ha hecho cosa; el producto es la objetivación del trabajo. La realización del trabajo es su objetivación. Esta realización del trabajo aparece en el estadio de la Economía Política como desrealización del trabajador, la objetivación como pérdida del objeto y servidumbre a él, la apropiación como extrañamiento, como enajenación ${ }^{12}$.

11 El estudio de los Manuskripte puede volver a tomar un papel central en nuestro contexto europeo precisamente porque, durante mucho tiempo, fueron olvidados o mal leídos. Sin embargo, en Latinoamérica sí que existe una tradición de lectura de estas investigaciones en la dirección de una reformulación del concepto de alienación/ desposesión en relación a una dignificación del trabajo asalariado. Reconociendo esta superioridad teórica a esas lecturas latinoamericanas, ocuparse en profundidad de ellas requeriría otra investigación independiente. Sin embargo, una cierta comparación entre los textos de Marx y las lecturas mencionadas se tendría que confrontar con los movimientos de izquierda latinoamericanos de los últimos años. Si tomamos los Manuskripte como un programa de refundación del marxismo, esos mismos movimientos sociales no podrían más que caer bajo una crítica radical, la cual parece haber sido olvidada por gran parte de la izquierda europea. Aun así, es necesario reconocer la superioridad teórica de las lecturas de estos textos en el mundo latinoamericano. Para dos ejemplos perfectos de esta superioridad teórica, véase Enrique Dussel, Hacia un Marx desconocido. Un comentario de los Manuscritos del 61-63, Siglo XXI, Ciudad de México, 1988; Néstor Kohan, Nuestro Marx, La oveja roja, Madrid, 2013.

12 Marx, Manuscritos: economía y filosofia, pp. 105-106. "Der Gegenstand, den die Arbeit produziert, ihr Produkt, tritt ihr als ein fremdes Wesen, als eine von dem Produzenten unabhängige Macht gegenüber. Das Produkt der Arbeit ist die Arbeit, die sich in einem Gegenstand fixiert, sachlich gemacht hat, es ist die Vergegenständlichung der Arbeit. Die Verwirklichung der Arbeit ist ihre Vergegenständlichung. Diese Verwirklichung der Arbeit erscheint in dem nationalokönomischen Zustand als Entwirklichung des Arbeiters, die Vergegenständlichung als Verlust und Knechtschaft des Gegenstandes, die Aneignung als Entfremdung, als Entäusserung". Karl Marx y Friedrich Engels, Gesamstausgabe (MEGA), I. Abteilung, Band 2, Dietz Verlag, Berlin, 2009, p. 656; MEW, vol. 40, Dietz Verlag, Berlin, 1968, p. 512. Para otra versión de esta misma tesis ya en el contexto de la crítica de la economía política, véase Karl Marx, Ökonomische Manuskripte 1863-1867, en MEGA, II. Abteilung-"Das Kapital" und Vorarbeiten, Band 4, Dietz Verlag, Berlin, 1988, pp. 121-122. Para las citas se han tenido en cuenta las traducciones del Fondo de Cultura Económica (1982), de Alianza Editorial a cargo de Ángel Prior Olmos (1998), de Colihue (2004) y la clásica de Alianza a cargo de Francisco Rubio Llorente (1979) que se ha tomado como la más acabada. Por una cuestión de unidad de estilo, se ha preferido consultar en todo momento como 
Desrealización, pérdida del objeto y extrañamiento son los tres elementos que aparecen en la relación del trabajador con respecto al producto de su trabajo. Existe aquí una dialéctica entre el trabajador y el mundo que crea: cuanto más produce su mundo, más extraño se le aparece. En este comienzo del despliegue del concepto, Marx ya establece una idea profundamente importante de su crítica al capitalismo: el trabajador, antes productor independiente, está ahora condenado al trabajo industrial capitalista para poder garantizarse su subsistencia. Sin embargo, esto significa, necesariamente, que cuanto más intenta garantizársela dentro de la producción capitalista, más extraño es el mundo que crea.

El trabajador aparece convertido ya en otra figura social que no es la del trabajador propiamente dicho, esto es, no es aquel sujeto que ejerce su actividad para producir un mundo y una vida propi $\mathrm{a}^{13}$. El trabajador queda rebajado a la categoría de mercancía:

El trabajador se convierte en una mercancía tanto más barata cuantas más mercancías produce. La desvalorización del mundo humano crece en razón directa de la valorización del mundo de las cosas. El trabajo no sólo produce mercancías; se produce también a sí mismo y al obrero como mercancía, y justamente en la proporción en que produce mercancías en general ${ }^{14}$.

La conversión del trabajador en mercancía en este primer estadio de la alienación significa que el propio proletariado queda igualado a una mera categoría económica, esto es, queda conceptualizado como una pieza dentro del proceso de valorización. El modo en el que se introduce en el mismo proceso de producción es a través de su conversión, o igualación, a la mercancía como fuerza de trabajo. En definitiva, el trabajador se iguala con aquello que produce: las mercancías produciendo más mercancías ${ }^{15}$.

Esta conversión del sujeto en mercancía significa que el individuo ya no es entendido como un ser con necesidades por cumplir, sino como un mero componente en el proceso de producción. Por eso, las necesidades vitales más inmediatas dejan de estar garantizadas en el momento en que entra en el proceso de producción de riqueza:

texto básico de la investigación los originales alemanes de MEW (1968) y MEGA (2009), teniendo siempre a mano las diferentes traducciones.

13 No hay que olvidar que Marx está aquí todavía preso de una visión del trabajo próxima a la del artesano tradicional. En este sentido, puede todavía distinguir entre el productor como aquel que producía dentro de una organización del trabajo más o menos cooperativa y autónoma y la visión del trabajador, del proletario, que ya está sometido a la disciplina del capital. Sobre el modelo de trabajo pre-capitalista, cf. Fredric Jameson, Las variaciones de Hegel. Sobre la Fenomenología del espíritu, trad. de David Sánchez Usanos, Akal, Madrid, 2015, pp. 63-79.

14 Marx, Manuscritos: economía y filosofia, pp. 105-106. "Der Arbeiter wird eine um so wohlfeilere Ware, je mehr Waren er schafft. Mit der Verwertung der Sachenwelt nimmt die Entwertung der Menschenwelt in direkten Verhältnis zu. Die Arbeit produziert nicht nur Waren; sie produziert sich selbst und den Arbeiter als eine Ware, und zwar in dem Verhältnis, in welchem sie überhaupt Waren produziert”. MEGA, I. Abteilung, Band 2, pp. 655656; MEW, vol. 40, pp. 511-512.

15 Como se sabe, el esquema de Das Kapital M-M'será, exactamente, la reproducción de esta idea, pero ya dentro de la crítica de la economía política. Sobre el modo en que Marx desarrolla este concepto, véase MEW, vol. 23, Dietz Verlag, Berlin, 1962, p. 170. Este sería otro argumento para derribar, de una vez por todas, la idea de la cesura metodológica entre el joven Marx y el Marx maduro. 
Hasta tal punto aparece la realización del trabajo como desrealización del trabajador, que éste es desrealizado hasta llegar a la muerte por inanición. La objetivación aparece hasta tal punto como pérdida del objeto que el trabajador se ve privado de los objetos más necesarios no sólo para la vida, sino incluso para el trabajo. Es más, el trabajo mismo se convierte en un objeto del que el trabajador sólo puede apoderarse con el mayor esfuerzo y las más extraordinarias interrupciones. La apropiación del objeto aparece en tal medida como extrañamiento, que cuantos más objetos produce el trabajador, tantos menos alcanza a poseer y tanto más sujeto queda a la dominación de su producto, es decir, del capital ${ }^{16}$.

La lógica que opera aquí consiste en que cuanto más produce el trabajador, más extraño le es el producto de su trabajo y más barato resulta él mismo como mercancía. Por ello, podría deducirse que el trabajo, dentro del modo de producción capitalista, desvaloriza necesariamente al trabajador en cuanto que su actividad le resulta más alienada en relación directamente proporcional con su capacidad productiva.

Aquí queda establecida ya la dialéctica del trabajo asalariado: el proletariado debe trabajar para garantizarse una vida, pero cuanto más trabaja, menos se realiza a sí mismo, es decir, más extraño se vuelve para sí. A partir de aquí, la dialéctica despliega toda la problemática del trabajo en este primer aspecto de la alienación: si el trabajo se encuentra en una situación dialéctica con el trabajador, ¿es el trabajo asalariado un medio de liberación? ¿No queda limitado aquí el trabajo asalariado a un elemento funcional del proceso de valorización capitalista, ya que cuanto más produce el trabajo más desrealizado queda el productor mismo? Por eso, aquí se presenta el primer problema de la crítica del trabajo asalariado: el proyecto de una lucha por la dignidad del trabajo dentro de un proyecto anticapitalista como es el marxismo pierde todo sentido. A partir de este esquema, la lucha por el derecho al trabajo está radicalmente en contra del proyecto de crítica al capitalismo que está desarrollando Marx aquí.

De aquí en adelante, no hay más que preguntas ante las cuales los Manuskripte parecen no ofrecer una respuesta clara: ¿cómo sería ese tipo de actividad en la cual los sujetos tendrían una relación directa con aquello que producen? ¿Cómo sería un tipo de producción en el que cada individuo produjera de acuerdo a una red de producción que, de forma espontánea, creara todos los bienes necesarios para una sociedad determinada? ¿No estaría aquí Marx preso de una cierta robinsonada, en la cual no quedaría bien definido el modelo social de producción, dejando abierto, más bien, el problema de concebir un conjunto de productores individuales que no han establecido, todavía, los fundamentos de una producción social?

16 Marx, Manuscritos: economía y filosofia, pp. 105-106. "Die Verwirklichung der Arbeit erscheint so sehr als Entwirklichung, dass der Arbeiter bis zum Hungertode entwirklicht wird. Die Vergegenständlichung erscheint so sehr als Verlust des Gegenstandes, dass der Arbeiter der notwendigsten Gegenstände, nicht nur des Lebens, sondern auch der Arbeitsgegenstände, beraubt ist. Ja, die Arbeit selbst wird zu einem Gegenstand, dessen er nur mit der grössten bemächtigen kann. Die Aneignung des Gegenstandes erscheint so sehr als Entfremdung, dass, je mehr Gegenstände der Arbeiter produziert, er um so weniger besitzen kann und um so mehr unter die Herrschaft seines Produkts, des Kapitals, gerät”. MEGA, I. Abteilung, Band 2, pp. 656-657; MEW, vol. 40, pp. 511-512. 


\section{2. ¿Qué significa "construir un mundo"? El problema del reconocimiento}

En definitiva, la tragedia del proceso de alienación en esta primera etapa es que el mundo que produce el proletariado no solo acaba por volverse ajeno al trabajador mismo, sino que llega a convertirse en una forma de vida hostil:

Todas estas consecuencias están determinadas por el hecho de que el trabajador se relaciona con el producto de su trabajo como un objeto extraño. Partiendo de este supuesto, es evidente que cuanto más se vuelca el trabajador en su trabajo, tanto más poderoso es el mundo extraño, objetivo que crea frente a sí y tanto más pobres son él mismo y su mundo interior, tanto menos dueño de sí mismo es. Lo mismo sucede en la religión. Cuanto más pone el hombre en Dios, tanto menos guarda en sí mismo. El trabajador pone su vida en el objeto, pero a partir de entonces ya no le pertenece a él, sino al objeto. Cuanto mayor es la actividad, tanto más carece de objetos el trabajador. Lo que es el producto de su trabajo, no lo es él. Cuanto mayor es, pues, este producto, tanto más insignificante es el trabajador. La enajenación del trabajador en su producto significa no solamente que su trabajo se convierte en un objeto, en una existencia exterior, sino que existe fuera de él, independiente, extraño, que se convierte en un poder independiente frente a él; que la vida que ha prestado al objeto se le enfrenta como cosa extraña y hostil ${ }^{17}$.

De este modo, se introduce el problema del reconocimiento: ¿qué significa que el trabajador no reconoce su mundo como propio? Básicamente, que no lo identifica como el producto de su actividad, que no lo entiende como fruto de su trabajo. Por definición, dentro del esquema de la dialéctica del trabajo asalariado, el robo sistemático del producto del trabajo es la consecuencia de la necesidad del trabajador de venderse como fuerza de trabajo para poder sobrevivir.

Sin embargo, este no es el único problema que se plantea en torno a la cuestión del reconocimiento. La producción de un mundo propio por parte del conjunto de los trabajadores se tiene que entender como un acto colectivo, es decir, debe ser el proceso por el cual el proletariado reconoce al conjunto de objetos producidos por ese colectivo: el mundo que crea a través del trabajo en cuanto clase ${ }^{18}$. Paradójicamente, aquí Marx da por supuesto un elemento que luego cristalizará dentro de la organi-

17 Marx, Manuscritos: economía y filosofía, pp. 105-106. "In der Bestimmung, dass der Arbeiter zum Produkt seiner Arbeit als einem fremden Gegenstand sich verhält, liegen alle diese Konsequenzen. Denn es ist nach dieser Voraussetzung klar: Je mehr der Arbeiter sich ausarbeitet, um so mächtiger wird die fremde, gegenständliche Welt, die er sich gegenüber schafft, um so ärmer wird er selbst, seine innre Welt, um so weniger gehört ihm zu eigen. Es ist ebenso in der Religion. Je mehr der Mensch in Gott setzt, je weniger behält er in sich selbst. Der Arbeiter legt sein Leben in den Gegenstand; aber nun gehört es nicht mehr ihm, sondern dem Gegenstand. Je grösser also diese Tätigkeit, um so gegenstandsloser ist der Arbeiter. Was das Produkt seiner Arbeit ist, ist er nicht. Je grösser also dieses Produkt, je weniger ist er selbst. Die Entäusserung des Arbeiters in seinem Produkt hat die Bedeutung, nicht nur, dass seine Arbeit zu einem Gegenstand, zu einer äussern Existenz wird, sondern dass sie ausser ihm, unabhängig, fremd von ihm existiert und eine selbständige Macht ihm gegenüber wird, dass das Leben, was er dem Gegenstand verliehn hat, ihm feindlich und fremd gegenübertritt". MEGA, I. Abteilung, Band 2, pp. 657-658; MEW, vol. 40, pp. 512-513.

18 Para poder entender esta tesis, no hay que olvidar que, en otros textos, como el capítulo VI inédito de Das Kapital, Marx no deja de recordar con insistencia cómo la transformación de los medios de producción y las fuerzas productivas solo llegan a convertirse en capital en determinadas condiciones históricas, de tal forma que se abre paso esa idea del "comunismo del capital" que desarrollará más adelante. Sobre la determinación histórica de las 
zación totalitaria de la producción en el marxismo soviético: se le supone a la clase trabajadora una unidad de conciencia por la cual el conjunto de objetos producidos será reconocido por toda la clase como algo propio ${ }^{19}$.

Sin embargo, esta perspectiva elimina la posibilidad de brechas dentro de ese proceso de reconocimiento entre el trabajador y el mundo que produce: ¿es posible que dentro de la misma clase trabajadora no haya un reconocimiento intercambiable de los productos producidos por toda la clase en su conjunto $?^{20}$. En el mundo soviético esta unidad en el reconocimiento venía dada desde arriba, de la propia organización del Estado, es decir, de un modo de organizar la producción en el que, por definición, todo trabajo ya era producción no alienada. De este modo, las posibles fisuras dentro de la unidad obrera desaparecían bajo el mando de un poder que se definía a sí mismo, y de entrada, como la organización socialista del trabajo asalariado.

En este marco es donde se puede insertar la reavivación contemporánea del problema del comunismo, es decir, la reformulación de la pregunta por cómo entender ese concepto marxiano en nuestra contemporaneidad ${ }^{21}$. Sin embargo, lo cierto es que, en general, la estrategia que más se repite es la de volver a convertir al marxismo en una crítica de la economía política, es decir, volver a los fundamentos del marxismo más ortodoxo, entendiendo que el problema no ha sido que haya dejado de ser útil socialmente, sino que la Postmodernidad lo ha convertido en un instrumento teórico carente de fuerza de transformación ${ }^{22}$.

Sin embargo, y aquí se muestra otro de los aspectos de la importancia de los Manuskripte, esta estrategia de vuelta a la crítica de la economía política deja sin resolver la dialéctica del trabajo asalariado: por mucho que los análisis del proceso de valorización demuestren la lógica de la obtención de plusvalía, no llegan a tratar el problema de cómo el mismo trabajo asalariado es la fuente principal de reproducción del capital. En definitiva, la vuelta a la economía política no garantiza de ninguna

condiciones formales capitalistas, véase Marx, Ökonomische Manuskripte 1863-1867, en MEGA, II. Abteilung, Band 4, pp. 57-58.

19 El momento totalitario de la organización soviética del trabajo remite a una de las distinciones más importantes desarrolladas en el capítulo VI inédito de Das Kapital como es la de "subsunción real/subsunción formal del trabajo en el capital”. Según este análisis, lo esencial del modo en el que las formas pre-capitalistas de producción se insertan definitivamente en el modo capitalista se distingue por dos elementos: 1) La relación puramente monetaria entre el que se apropia el plus trabajo y el que lo suministra; 2) Las condiciones objetivas y subjetivas del trabajo se le enfrentan al obrero como capital (véase ibid., pp. 104 y ss.). Estas dos tesis significan, en relación con la cuestión del reconocimiento, que se establece una relación de identidad absoluta entre el modo de producción y el mundo que produce. En relación a los Manuskripte, esta tesis viene a situarse en el momento pesimista de una victoria absoluta de un modo concreto e histórico de producción por convertirse en hegemónico y por haber conseguido crear un mundo a su imagen y semejanza. En este sentido, introducir la cuestión del reconocimiento implica estudiar las formas de romper el proceso de la identidad absoluta entre capitalismo y mundo social.

20 En el mismo texto Marx se ocupa de esta idea a través del análisis de las condiciones históricas previas que dieron lugar al capitalismo. Más en concreto, se ocupa de las formas de producción en común que se desarrollaban antes de su apropiación capitalista y de cómo le permitía al capital economizar los gastos de producción ya que la eficacia de estas condiciones productivas era mayor que la forma dispersa. Véase ibid., pp. 107-108.

21 Un ejemplo de esta reavivación del problema del comunismo son las dos conferencias organizadas por Žižek en torno a esta cuestión. Cf. Slavoj Žižek (ed.), La idea de comunismo. The New York Conference (2011), trad. de Juan Gorostidi Mungia y Francisco López Martín, Akal, Madrid, 2014.

22 Este es, precisamente, el argumento de uno de los últimos libros de Žižek. Cf. Slavoj Žižek, Absolute Recoil: Towards a New Foundation of Dialectical Materialism, Verso, London, New York, 2015. 
manera superar los errores históricos del socialismo real, en tanto que no ponen la crítica al trabajo asalariado en el centro de la problemática del anticapitalismo.

Por este motivo, los Manuskripte se sitúan en un momento mucho más adelantado dentro de la propia teoría marxista que gran parte de los conceptos desarrollados posteriormente. Pese a que la crítica no sabe cómo resolver la dialéctica entre trabajo alienado y necesidad de la actividad productiva, son importantes porque ponen ese problema en el centro del proyecto de superación del capitalismo. Por eso, la débil tradición marxiana que surgió de los análisis de los Manuskripte, o que se ha creído heredera de ellos, ha sido siempre aquella que supo ver en el socialismo real un modo conservador de entender el proyecto marxista, es decir, una forma de apropiación del aparato productivo del Estado capitalista para usar la fuerza de explotación en favor propio.

\section{Enajenación en el acto de la producción: reducción a la animalidad y desposesión de los medios de producción}

\subsection{Reducción a la animalidad}

En este segundo aspecto de la "alienación", es en el mismo acto de la producción en el que el trabajador ya se hace extraño a sí mismo. Esta enajenación consiste en que es la propia actividad del trabajo la que es desposeída del trabajador:

El trabajo es externo al trabajador, es decir, no pertenece a su ser;...en su trabajo el trabajador no se afirma, sino que se niega; no se siente feliz, sino desgraciado; no desarrolla una libre energía física y espiritual, sino que mortifica su cuerpo y arruina su espíritu. Por eso, el trabajador sólo se siente en sí fuera del trabajo y en el trabajo fuera de sí. Está en lo suyo cuando no trabaja y cuando trabaja no está en lo suyo. Su trabajo no es, así, voluntario, sino forzado, trabajo forzado. Por eso no es la satisfacción de una necesidad, sino solamente un medio para satisfacer las necesidades fuera del trabajo. Su carácter extraño se evidencia claramente en el hecho de que tan pronto como no existe una coacción física o de cualquier otro tipo se huye del trabajo como de la peste. El trabajo externo, el trabajo en que el hombre se enajena, es un trabajo de autosacrificio, de ascetismo ${ }^{23}$.

No es que la desposesión del objeto de trabajo se dé de una forma aislada dentro de una actividad gestionada por los productores, sino que es esta misma actividad la que también se encuentra desposeída. Si tenemos en cuenta el papel que Marx otorga

23 Marx, Manuscritos: economía y filosofía, p. 109. "Erstens, dass die Arbeit dem Arbeiter äusserlich ist, d.h. nicht zu seinem Wesen gehört, dass er sich daher in seiner Arbeit nicht bejaht, sondern verneint, nicht wohl, sondern unglücklich fühlt, keine freie physische und geistige Energie entwickelt, sondern seine Physis abkasteit und seinen Geist ruiniert. Der Arbeiter fühlt sich daher erst ausser der Arbeit bei sich und in der Arbeit ausser sich. $\mathrm{Zu}$ Hause ist er, wenn er nicht arbeitet, und wenn er arbeitet, ist er nicht zu Haus. Seine Arbeit ist daher nicht freiwillig, sondern gezwungen, Zwangsarbeit. Sie ist daher nicht die Befriedigung eines Bedürfnisses, sondern sie ist nur ein Mittel, um Bedürfnisse ausser ihr zu befriedigen. Ihre Fremdheit tritt darin rein hervor, dass, sobald kein physischer oder sonstiger Zwang existiert, die Arbeit als eine Pest geflohen wird. Die äusserliche Arbeit, die Arbeit, in welcher der Mensch sich entäussert, ist eine Arbeit der Selbstaufopferung, der Kasteiung". MEGA, I. Abteilung, Band 2, pp. 661-662; MEW, vol. 40, pp. 514-515. 
al trabajo como actividad fundamental del sujeto, no es de extrañar que conciba aquí la desposesión de la actividad del trabajador como la pérdida del trabajador de sí mismo. ¿Cómo enfrentarse con el producto de su actividad como con algo extraño si en el acto mismo de la producción no se hiciese ya ajeno a sí mismo?

En este momento, aparece una figura que más tarde será tematizada en ciertas corrientes de la filosofía postestructuralista: el animal ${ }^{24}$. ¿Cómo puede liberarse el trabajador de las condiciones de trabajo del modo de producción capitalistas, es decir, como puede liberarse de la desposesión y el extrañamiento del producto de su trabajo y de la propia actividad? A través de su reducción a la animalidad:

De esto resulta que el hombre (el trabajador) sólo se siente libre en sus funciones animales, en el comer, beber, engendrar y todo lo más en aquello que toca a la habitación y al atavío, y en cambio en sus funciones humanas se siente como animal. Lo animal se convierte en lo humano y lo humano en lo animal.

Comer, beber y engendrar, etc., son realmente también auténticas funciones humanas. Pero en la abstracción que las separa del ámbito restante de la actividad humana y las convierte en fin único y último son animales ${ }^{25}$.

La reducción a la animalidad como producto de la desposesión de la actividad productiva reintroduce una temática que se puede rastrear hasta el principio de la doctrina liberal contra la cual se sitúa el materialismo histórico de Marx y que encuentra aquí una de sus primeras formulaciones. En ciertas versiones tempranas del liberalismo, como la de Thomas Hobbes (1588-1679), la cuestión de la reducción a la animalidad se circunscribe al marco de la guerra civil generalizada, a ese "estado de naturaleza" en el cual el individuo todavía no ha encontrado el momento de civilización que le haga salir de esa condición salvaje ${ }^{26}$.

24 Tal vez haya sido Jacques Derrida (1930-2004) quien haya tratado más en profundidad la figura del animal, aunque, ciertamente, no dentro de un marco específicamente marxista. Cf. Jacques Derrida, The Beast \& the Sovereign, vol. I, trad. de Geoffrey Bennington, The University of Chicago Press, Chicago, 2009. Por otro lado, más adelante, en los materiales preparatorios para Das Kapital, como puede ser el Manuskript 1861-63, Marx no deja de presentar otra forma de alienación, esta vez igualando al trabajador con la máquina. De este modo, animal y máquina serían dos modos de despojar y dominar al trabajador en el proceso de producción. Sobre la relación entre alienación y maquinaria, véase Karl Marx, Progreso técnico y desarrollo capitalista (Manuscritos 1861-1863), trad. de Raúl Crisafio y Jorge Tula, Ediciones Pasado y Presente (Siglo XXI), Ciudad de México, 1992, pp. 91, 96, 161. En general, se podría decir que estos materiales, junto con el capítulo VI inédito, conforman una especie de puente entre la crítica al capitalismo presentada en estos Manuskripte de 1844 y Das Kapital, a la vez que suponen la adaptación de los contenidos de la filosofía alemana posthegeliana al marco de la crítica de la economía política.

25 Marx, Manuscritos: economía y filosofia, p. 109. "Es kömmt daher zu dem Resultat, dass der Mensch (der Arbeiter) nur mehr in seinen tierischen Funktionen, Essen, Trinken und Zeugen, höchstens noch Wohnung, Schmuck etc., sich als freitätig fühlt und in seinen menschlichen Funktionen nur mehr als Tier. Das Tierische wird das Menschliche und das Menschliche das Tierische”. MEGA, I. Abteilung, Band 2, p. 662; MEW, vol. 40, pp. 512-513, 515 .

26 Cf. Thomas Hobbes, Leviatán o la materia, forma y poder de un Estado eclesiástico y civil, trad. y ed. de Carlos Mellizo, Alianza, Madrid, 1999, pp. 119-129. Para la relación Marx-Hobbes, véase Julien Freund, "Karl Marx, un admirateur discret de Thomas Hobbes”: Revue européenne des sciences sociales, t. 20, n. ${ }^{\circ} 61$ (1982), pp. 349-359. Esta relación Hobbes-Marx está muy presente en la crítica al proyecto ilustrado de Theodor Adorno (1903-1969) y Max Horkheimer (1895-1973) en Dialektik der Aufklärung. Véase Theodor Adorno y Marx Horkheimer, Dialektik der Aufklärung, Fischer Verlag, Frankfurt, 2004. Es también la crítica en términos de crisis de un proyecto de civilización determinado el que se puede extraer de los Manuskripte: ya no se trataría de la posibilidad de domar las fuerzas productivas y las contradicciones del capitalismo y la cultura de la Ilustración, sino más bien, y antes que nada, de establecer las contradicciones esenciales de ese modo de producción de vida en común. 
En el caso de Hobbes, el Leviathan aparece como esa mediación institucional que posibilitará la salida del estado de naturaleza, es decir, que acabará, de alguna forma, con la descarnada lucha por la supervivencia. A través del contrato social, los miembros de una sociedad delegan su poder en manos de una exterioridad que servirá como juez imparcial a través del cual las disputas sociales puedan resolverse de forma más o menos pacífica ${ }^{27}$.

Sin embargo, la descripción que hace Marx de la relación entre la libertad práctica y la reducción a la animalidad dentro de la crítica al trabajo asalariado implica ya una impugnación en acto a la doctrina liberal del estado de naturaleza. El liberalismo, por lo menos en las primeras versiones como la de Hobbes, encontró su mayor legitimación en el hecho de haber introducido un elemento civilizatorio en un estado de violencia continua de unos contra otros. No obstante, ahora, la crítica de la economía política del naciente liberalismo descubre que, paradójicamente, la organización de la producción reintroduce la animalidad de un modo muy determinado: ya no es la lucha directa por la supervivencia sino el proceso por el cual la desposesión de la actividad del trabajador le despoja de toda posibilidad de autoafirmación, de tal forma que no le deja otra salida al productor que convertirse en un animal para poder encontrar algún tipo de libertad práctica.

En este sentido, se puede entender sin muchos problemas cómo la crítica de la economía política está ejerciendo ya aquí, en su primera versión todavía pegada a los conceptos de la filosofía hegeliana y feuerbachiana, una crítica al relato que el liberalismo había introducido del nacimiento del Estado y de la sociedad moderna. Tal vez el contrato social introdujo cierto elemento civilizatorio, pero al precio de dejar entrar por la puerta de atrás el fantasma de una animalidad de la cual el liberalismo quería ser su superación pero que ha acabado por ser su confirmación.

\subsection{Recuperación de los medios de producción: el consejismo obrero}

Pero no solo aparece la dimensión de la animalidad dentro de este segundo aspecto de la alienación en el trabajo asalariado. El proceso al que se refiere Marx aquí tiene que ver también con la desposesión de los medios de producción. Todos los instrumentos con los que los productores pueden llevar a cabo su actividad no les pertenecen, son de otro ${ }^{28}$, pertenecen al capitalista. De este modo, lo que debería ser el medio con el que cada sujeto trabaja para garantizar su subsistencia se convierte en una actividad que pertenece a otro y cuyo producto también le pertenece a este.

Cuando Marx habla de la desposesión de la actividad está hablando también de la enajenación de los medios de producción, es decir, de la tecnología con la que el trabajador produce. Este proceso, por lo tanto, encuentra aquí una base material, que es

27 Véase Hobbes, Leviatán o la materia, forma y poder de un Estado eclesiástico y civil, pp. 119 y ss. Desde un punto de vista meramente teórico, la discusión en torno al estado de naturaleza concierne a ese relato del capitalismo como un momento de civilización, conectado con el nacimiento del estado moderno en el siglo diecisiete, que es lo que Hobbes describe en el Leviatán. La reintroducción de esta temática de la animalidad tiene la profundidad suficiente como para poder preguntarnos si el avance histórico no vendrá dado por la superación de los procesos de alienación descritos aquí en los Manuskripte: ¿el futuro de la teoría y práctica emancipatoria no vendrá dada por la impugnación del componente civilizatorio del capitalismo? No hay que olvidar, por otro lado, que en algunos textos el propio Marx se convierte en un defensor de la capacidad del capital por diluir formas de opresión tradicionales. Sobre este asunto, en relación con la conquista de la India por parte de los ingleses en 1853, véase MEW, vol. 9, Dietz Verlag, Berlin, 1975, pp. 132 y ss.

28 Aquí ya se va introduciendo la temática de la alteridad que Marx desarrolla en el cuarto aspecto de la alienación: los medios de producción ya se personifican en un individuo que aparece como opuesto al productor. 
la relación jurídica de propiedad por la cual dichos medios pertenecen al capitalista, mientras que el trabajador sólo posee su fuerza de trabajo ${ }^{29}$.

Es aquí donde se conecta este segundo aspecto de la alienación con la crítica al estatalismo y a la recuperación de los medios de producción. La centralización de la economía ha sido, en gran parte, el proyecto histórico del socialismo real. Se ha entendido históricamente que la posesión de los medios productivos por parte del Estado era ya la gestión de estos mismos medios por parte de los trabajadores. El silogismo es relativamente sencillo: el estado de los trabajadores no solo representa a los trabajadores sino que es el conjunto de los trabajadores gobernándose a sí mismos; los medios de producción están recuperados por el estado de los trabajadores; por lo tanto, los medios de producción pertenecen a los trabajadores ${ }^{30}$.

No obstante, la historia del socialismo real ha demostrado algo muy diferente. Se ha producido una falsa identificación entre estado y proletariado, por la cual lo que pertenecía a uno, automáticamente pertenecía al otro. En la práctica, no solo los medios de producción sino toda la vida social acabó por ser dirigida por una burocracia obrera que, al querer llevar hasta el final la supuesta identificación con su pueblo, acabó por eliminar cualquier posibilidad de que esa misma identificación fuera quebrada por algún elemento crítico.

Desde esta denuncia de Marx de la desposesión de la actividad dentro del trabajo asalariado, lo que se puede entender es que el proyecto del comunismo no puede consistir en algo diferente al hecho de que los mismos trabajadores sean dueños de los medios con los que producir. Aquí todavía no hay rastro de una aspiración a una centralización de la economía que pudiera acabar con esa "anarquía de la producción" tan característica del capitalismo; aquí existe el reconocimiento de que sin los medios de producción el productor no es nada.

No es de extrañar que, en una muy pequeña parte, el proyecto del comunismo haya consistido en la recuperación de los centros de producción. La historia de esa corriente que se ha llamado "consejismo obrero" no es más que la historia del movimiento por el cual no solo los trabajadores toman el control directo de la producción, sino, principalmente, toman la posesión de los medios de producción ${ }^{31}$.

Desde los análisis de Marx en estos Manuskripte y después de las experiencias históricas del consejismo obrero, ahora podemos preguntarnos por la validez de esta experiencia: ¿en qué medida la democracia obrera de los consejos ha podido constituirse en alternativa viable al centralismo económico? Más allá de los límites históri$\cos$ que ha tenido esta práctica ${ }^{32}$, lo cierto es que podría sacarse la conclusión de que

29 Sobre el papel de la propiedad privada en todo el esquema de la enajenación, véase Marx, Manuscritos: economía y filosofia, p. 116. Para un ejemplo de interpretación errónea de la propiedad como base del trabajo alienado, véase Daniel Bell, "The Rediscovery of Alienation: Some Notes along the Quest for the Historical Marx": The Journal of Philosophy, vol. 56, n. ${ }^{\circ} 24$ (1959), p. 939.

30 Para una exposición de esta tesis, junto con una crítica que va más allá de la tradicional distinción público/privado, véase Christian Laval y Pierre Dardot, Común. Ensayo sobre la revolución en el siglo XXI, trad. de Alfonso Díez, Gedisa, Barcelona, 2015, pp. 69-108.

31 Para entender en qué consisten los consejos obreros, cf. Anton Pannekoek, Los consejos obreros, trad. de Luis López Gutiérrez, Zero Zyx, Bilbao, 1977.

32 Sobre la materialización histórica del consejismo obrero, no hay que dejar de reivindicar la experiencia de la Yugoslavia socialista, la cual, lejos de la influencia de la URSS, ensayó un modelo de democracia obrera al cual, todavía hoy, el marxismo no ha prestado la suficiente atención. Sobre el consejismo yugoslavo en relación a las formulaciones de Anton Pannekoek (1873-1960), véase Serge Bricianer, Pannekoek and the Workers's Councils, trad. de Malachy Carroll, Telos Press, Saint Louis, 1978. 
la autogestión obrera ${ }^{33}$ encuentra en estos textos de Marx su fundamentación dentro del materialismo histórico, aun en esta versión todavía demasiado "filosófica".

La experiencia del consejismo ha enseñado algo esencial para el pensamiento emancipador: el control directo del trabajo, y por tanto el control directo de la producción de los medios de vida, implica la superación efectiva del elemento de alienación y extrañación del trabajo asalariado. Sin embargo, la limitación de estas experiencias ha demostrado que el mismo principio debe adaptarse a las transformaciones históricas. ¿Cómo entender contemporáneamente el principio de la recuperación de los medios de producción en las sociedades postfordistas?

Aquí aparece la superioridad del carácter filosófico de los contenidos de los $\mathrm{Ma}$ nuskripte: pese a que el trabajo asalariado ha sufrido transformaciones radicales en relación con el modelo del trabajo fabril en el que trabaja el esquema de Marx, el principio se mantiene como la estrategia más acorde al proyecto de superación del capitalismo. Dicho de otro modo: pese al socialismo real, por un lado, y pese a las limitaciones históricas del consejismo obrero, el principio del retorno del poder de producción a los productores continúa siendo coherente con una práctica de superación anticapitalista. Lo que queda en la contemporaneidad es la gran tarea de entender qué significa esto en nuestras sociedades, en las cuales el trabajo asalariado ha mutado en formas complejas y dinámicas.

\section{Enajenación con respecto al modo genérico de la vida universal (Gattungswesen)}

El concepto marxiano de "trabajo" no solo implica una disposición antropológica a la actividad como medio de garantizar la libertad. Implica, también, la concepción del sujeto como el resultado de su propio trabajo ${ }^{34}$. Esto significa que el hombre se manifiesta como un "ser genérico" (Gattungswesen), como un ser perteneciente a una comunidad en la que se inserta y de la que encuentra el medio de su supervivencia a través de la exteriorización de sus fuerzas genéricas, es decir, del modo que tiene de relacionarse con el mundo:

Por eso precisamente es sólo en la elaboración del mundo objetivo en donde el hombre se afirma realmente como un ser genérico. Esta producción es su vida genérica activa. Mediante ella aparece la naturaleza como su obra y su realidad. El objeto del trabajo es, por eso, la objetivación de la vida genérica del hombre, pues éste se desdobla no sólo intelectualmente, como en la conciencia, sino activa y realmente, y se contempla a sí mismo en un mundo creado por é ${ }^{35}$.

33 La autogestión obrera es el principio político-filosófico a través del cual el consejismo obrero se forma como estrategia y táctica de organización de la clase obrera autónoma. Sobre este concepto, también en relación con la experiencia yugoslava, véase Sabine Bitter y Helmut Weber (eds.), Autogestion, or Henri Lefebvre in New Belgrade, Sternberg Press, Berlin, 2009.

34 Marx, Manuscritos: economía y filosofia, p. 190.

35 Ibid., p. 112. "Eben in der Bearbeitung der gegenständlichen Welt bewährt sich der Mensch daher erst wirklich als ein Gattungswesen. Diese Produktion ist sein werktätiges Gattungsleben. Durch sie erscheint die Natur als sein Werk und seine Wirklichkeit. Der Gegenstand der Arbeit ist daher die Vergegenständlichung des Gattungslebens des Menschen: indem er sich nicht nur wie im Bewusstsein intellektuell, sondern werktätig, wirklich 
El sujeto, en cuanto trabajador, es un ser genérico que va más allá de su individualidad. Cuando trabaja, no busca solo su experiencia privada, sino que busca su universalidad, realizarse como ser humano en aquello universal que le constituye como tal. En el trabajo alienado, el trabajador se enajena con respecto a su género porque aquello que le hace ser sujeto se suspende, se le aparece como extraño.

Del mismo modo, en cuanto ser genérico, se relaciona con su actividad de forma libre, esto es, no produce acuciado por la necesidad física, sino que realmente produce cuando está fuera de ella. Por esta razón, el trabajador puede desplegar modos diferentes de producción; ya no solo produce para garantizar su supervivencia, sino que produce para el deleite, como es el caso de la belleza. Si el trabajador se ve envuelto en una relación de necesidad con la naturaleza pierde su capacidad de ir más allá de esa misma necesidad natural, quedando igualado al animal que produce de forma inmediata.

Aquí se despliega otra vez la lógica de la reducción a la animalidad que se daba en la enajenación de la actividad pero bajo otra perspectiva. Ahora, el proceso de extrañamiento del componente genérico implica que la producción queda reducida a una relación de necesidad, en la que la lucha por la supervivencia es el único fin. La posibilidad antropológica, que al final es el proyecto último del comunismo, de producir no desde la necesidad sino desde la libertad se ve aquí impedida por la igualación absoluta entre actividad y trabajo asalariado dentro del modo de producción capitalista $^{36}$.

Este proceso es clave para poder entender este tercer aspecto de la "alienación" en los Manuskripte de Marx. Aquí, el trabajo enajenado es el resultado de una producción no social, insolidaria, no directamente comunitaria. Significa la "alienación" de la esencia del hombre:

El hombre es un ser genérico no sólo porque en la teoría y en la práctica toma como objeto suyo el género, tanto el suyo propio como el de las demás cosas, sino también, y esto no es más que otra expresión para lo mismo, porque se relaciona consigo mismo como el género actual, viviente, porque se relaciona consigo mismo como un ser universal y por eso libre...La vida genérica se convierte en medio de la vida individual. En primer lugar, hace extrañas entre sí la vida genérica y la vida individual, en segundo término convierte a la primera, en abstracto, en fin de la última, igualmente en su forma extrañada y $\operatorname{abstracta}^{37}$.

verdoppelt und sich selbst daher in einer von ihm geschaffnen Welt anschaut". MEGA, I. Abteilung, Band 2, Band 2, p. 667; MEW, vol. 40, p. 517.

36 En un pasaje del tomo III de Das Kapital, el propio Marx conecta la reducción de la jornada de trabajo con el paso del reino de la necesidad al reino de la libertad, es decir, otra vez toma categorías de la tradición filosófica, en este caso de la filosofía de las antinomias de Inmanuel Kant (1724-1804), para explicar la necesidad esencial de la crítica al trabajo asalariado. Cf. MEW, vol. 25, Dietz Verlag, Berlin, 1964, p. 828. Para un comentario sobre este fragmento, véase el comentario de Pier Aldo Rovatti en Marx, Progreso técnico y desarrollo capitalista (Manuscritos 1861-1863), pp. 196-198.

37 Marx, Manuscritos: economía y filosofia, pp. 110-111. "Der Mensch ist ein Gattungswesen, nicht nur indem er praktisch und theoretisch die Gattung, sowohl seine eigne als die der übrigen Dinge, zu seinem Gegenstand macht, sondern — und dies ist nur ein anderer Ausdruck für dieselbe Sache-, sondern auch indem er sich zu sich selbst als der gegenwärtigen, lebendigen Gattung verhält, indem er sich zu sich einem universellen, darum freien Wesen verhält...sie macht ihm das Gattungsleben zum Mittel des individuellen Lebens. Erstens entfremdet sie das Gattungsleben und das individuelle Leben, und zweitens macht sie das letztere in seiner Abstraktion 
La vida productiva es vida genérica, es vida que crea vida. La actividad libre, consciente, es el carácter genérico del sujeto. La vida misma aparece solo como medio de vida. Cuando se le arrebata al ser humano su actividad se le está arrebatando, con ello, lo que le hace pertenecer a un género, es decir, se le arrebata su humanidad como especie animal. Sin embargo, a diferencia de este el ser humano es consciente de su actividad porque lo hace de una forma libre. Cuando esta actividad deja de ser consciente para pasar a estar determinada, el ser humano queda igualado al animal.

Si en relación al extrañamiento y desposesión de la actividad misma ya aparecía, amenazante, la reducción a la animalidad, aquí aparece en toda su crudeza:

Pues, en primer término, el trabajo, la actividad vital, la vida productiva misma, aparece ante el hombre sólo como un medio para la satisfacción de una necesidad, de la necesidad de mantener la existencia física. La vida productiva es, sin embargo, la vida genérica. Es la vida que crea vida. En la forma de la actividad vital reside el carácter dado de una especie, su carácter genérico, y la actividad libre, consciente, es el carácter genérico del hombre. La vida misma aparece sólo como medio de vida.

El animal es inmediatamente uno con su actividad vital. No se distingue de ella. Es ella. El hombre hace de su actividad vital misma objeto de su voluntad y de su conciencia. Tiene actividad vital consciente. No es una determinación con la que el hombre se funda inmediatamente. La actividad vital consciente distingue inmediatamente al hombre de la actividad vital animal. Justamente, y sólo por ello, es él un ser genérico ${ }^{38}$.

A diferencia del animal, el sujeto se relaciona con su propia actividad como algo que es objeto de su voluntad y de su conciencia. Es dueño de su actividad porque es consciente de ella. No es una determinación del propio individuo ante la cual no puede hacer nada. La controla porque es libre. Por eso, solo es su propia vida objeto para él. Ahí reside la conexión con el género:

Es cierto que también el animal produce. Se construye un nido, viviendas, como las abejas, los castores, las hormigas, etc. Pero produce únicamente lo que necesita inmediatamente para sí o para su prole; produce unilateralmente, mientras que el hombre produce universalmente; produce únicamente por mandato de la necesidad física inmediata, mientras que el hombre produce incluso libre de la necesidad física y sólo produce realmente liberado de ella; el animal se produce sólo a sí

zum Zweck des ersten, ebenfalls in seiner abstrakten und entfremdeten Form". MEGA, I. Abteilung, Band 2, pp. 663-665; MEW, vol. 40, pp. 515-516.

38 Marx, Manuscritos: economía y filosofia, pp. 111-112. "Denn erstens erscheint dem Menschen die Arbeit, die Lebenstätigkeit, das produktive Leben selbst nur als ein Mittel zur Befriedigung eines Bedürfnisses, des Bedürfnisses der Erhaltung der physischen Existenz. Das produktive Leben ist aber das Gattungsleben. Es ist das Leben erzeugende Leben. In der Art der Lebenstätigkeit liegt der ganze Charakter einer species, ihr Gattungscharakter, und die freie bewusste Tätigkeit ist der Gattungscharakter des Menschen. Das Leben selbst erscheint nur als Lebensmittel. / Das Tier ist unmittelbar eins mit seiner Lebenstätigkeit. Es unterscheidet sich nicht von ihr. Es ist sie. Der Mensch macht seine Lebenstätigkeit selbst zum Gegenstand seiner Wollens und seines Bewusstseins. Er hat bewusste Lebenstätigkeit. Es ist nicht eine Bestimmtheit, mit der er unmittelbar zusammenfliesst. Die bewusste Lebenstätigkeit unterscheidet den Menschen unmittelbar von der tierischen Lebenstätigkeit. Eben nur dadurch ist er ein Gattungswesen". MEGA, I. Abteilung, Band 2, pp. 665-666; MEW, vol. 40, pp. 516-517. 
mismo, mientras que el hombre reproduce la naturaleza entera; el producto animal pertenece inmediatamente a su cuerpo físico, mientras que el hombre se enfrenta libremente a su producto ${ }^{39}$.

En último término, lo que está describiendo aquí Marx es la capacidad del capitalismo de efectuar una transformación antropológica: el control de la propia actividad orientada a fines por una subjetividad que se cree libre queda sustituida, de forma violenta y sin ningún tipo de vuelta atrás, por la actividad como medio para garantizar la subsistencia. La propia transformación del trabajo modifica la producción y despliegue de la libertad por una vida subordinada a la mediación del salario ${ }^{40}$. El capitalismo consigue transformar las características que Marx atribuía al trabajo de una forma universal.

\section{Enajenación con respecto al otro: ¿una alteridad materialista?}

Existe una cuarta dimensión de la alienación que no ha sido demasiado tematizada por los estudios sobre los Manuskripte, ya que pertenece al desarrollo del tercer aspecto, es decir, al de la Gattungswesen, pero que, sin embargo, apunta a direcciones mucho más allá del ámbito del marxismo.

El trabajo se le aparece al trabajador como algo penoso, como algo que no le pertenece. La propiedad de ese trabajo le pertenece a otro. En la desposesión y extrañamiento del trabajo, en sus tres dimensiones, queda modificada la relación que cada trabajador establece con aquel que contrata trabajo, es decir, con el capitalista. Así, éste aparece como un otro ${ }^{41}$. El propio Marx entiende esta aparición de la alteridad como consecuencia de la enajenación:

Una consecuencia inmediata del hecho de estar enajenado el hombre del producto de su trabajo, de su actividad vital, de su ser genérico, es la enajenación del hombre respecto del hombre. Si el hombre se enfrenta consigo mismo, se enfrenta también al otro. Lo que es válido respecto de la relación del hombre con su trabajo, con el producto de su trabajo y consigo mismo, vale también para la relación del hombre con el otro y con el trabajo y el producto del trabajo del otro.

En general, la afirmación de que el hombre está enajenado de su ser genérico quiere decir que un hombre está enajenado del otro, como cada uno de ellos está enajenado de la esencia humana ${ }^{42}$.

39 Marx, Manuscritos: economía y filosofia, p. 112. "Zwar produziert auch das Tier. Es baut sich ein Nest, Wohnungen, wie die Biene, Biber, Ameise etc. Allein es produziert nur, was es unmittelbar für sich oder sein Junges bedarf; es produziert einseitig, während der Mensch universell produziert; es produziert nur unter der Herrschaft des unmittelbaren physischen Bedürfnisses, während der Mensch selbst frei vom physischen Bedürfnis produziert und erst wahrthaft produziert in der Freiheit von demselben; es produziert nur sich selbst, während der Mensch die ganze Natur reproduziert; sein Produkt gehört unmittelbar zu seinem physischen Leib, während der Mensch frei seinem Produkt gegenübertritt”. MEGA, I. Abteilung, Band 2, pp. 666-667; MEW, vol. 40, p. 517.

40 Sobre la cuestión de la subida de los salarios en relación directa a la superación de la explotación, véase Marx, $M a-$ nuscritos: economía y filosofia, p. 117. Quedaría así eliminada la subida de los salarios como meta de la emancipación de los trabajadores, ya que estos tienen como objetivo la mera supervivencia del obrero como mano de obra.

41 Cf. Marx, Ökonomische Manuskripte 1863-1867, en MEGA, II. Abteilung, Band 4, pp. 64-65.

42 Marx, Manuscritos: economía y filosofía, p. 113. "Eine unmittelbare Konsequenz davon, dass der Mensch dem Produkt seiner Arbeit, seiner Lebenstätigkeit, seinem Gattungswesen entfremdet ist, ist die Entfremdung des Menschen von dem Menschen. Wenn der Mensch sich selbst gegenübersteht, so steht ihm der andre Mensch ge- 
Para Marx, la aparición de la enajenación del ser genérico, de la vida genérica, significa que cada sujeto está enajenado del otro, del mismo modo que cada cual está enajenado de esa esencia humana resumida en el trabajo. Por eso, "en la relación del trabajo enajenado, cada hombre considera, pues, a los demás según la medida y la relación en la que él se encuentra consigo mismo en cuanto trabajador" ${ }^{\prime 3}$.

Después de exponer estos tres modos de enajenación, Marx presenta el momento práctico de la relación conceptual entre trabajo asalariado y enajenación:

Hemos partido de un hecho económico, el extrañamiento entre el trabajador y su producción. Hemos expuesto el concepto de este hecho: el trabajo enajenado, extrañado. Hemos analizado este concepto, es decir, hemos analizado simplemente un hecho económico.

Veamos ahora cómo ha de exponerse y representarse en la realidad ${ }^{44}$ el concepto de trabajo enajenado, extrañado.

Si el producto del trabajo me es ajeno, se me enfrenta como un poder extraño, entonces ¿a quién pertenece?

Si mi propia actividad no me pertenece; si es una actividad ajena, forzada, ¿a quién pertenece entonces?

A un ser otro que yo ${ }^{45}$.

La perspectiva que abre aquí Marx es muy importante: la relación de la enajenación no aparece como una fuerza anónima, sin sujeto, como una especie de estructura maquínica invisible que produjera la alienación y la desposesión del trabajador de todos los elementos que necesita para producir una vida. De una forma mucho más concreta, como momento práctico del concepto de "alienación", entiende que, en último término, la actividad del trabajo asalariado pertenece a otro sujeto. No a dioses $^{46}$, sino a otros hombres.

No sería exagerado afirmar que, desde esta perspectiva, Marx está aquí presentando la configuración material de la lucha de clases. ¿Dónde se desarrolla el conflicto que enfrenta a los dueños de los medios de producción con aquellos que los usan? ¿Qué proceso social ocurre para que se desencadene este conflicto? La alienación es el momento en el que explotan las contradicciones sociales, el momento en el que el

genüber. Was von dem Verhältnis des Menschen zu seiner Arbeit, zum Produkt seiner Arbeit und zu sich selbst, das gilt von dem Verhältnis des Menschen zum andren Menschen. / Überhaupt, der Satz, dass der Mensch seinem Gattungswesen entfremdet ist, heisst, dass ein Mensch dem andern, wie jeder von ihnen dem menschlichen Wesen entfremdet ist". MEGA, I. Abteilung, Band 2, p. 668; MEW, vol. 40, p. 518.

43 Marx, Manuscritos: economía y filosofia, p. 113.

44 Cursivas propias.

45 Marx, Manuscritos: economía y filosofia, p. 114. "Wir gingen aus von einem nationalökonomischen Faktum, der Entfremdung der Arbeiters und seiner Produktion. Wir haben den Begriff dieses Faktums ausgesprochen: die entfremdete, entäusserte Arbeit. Wir haben diesen Begriff analysiert, also bloss ein nationalökonomisches Faktum analysiert. / Sehn wir nun weiter, wie sich der Begriff der entfremdeten, entäusserten Arbeit in der Wirklichkeit aussprechen und darstellen muss. / Wenn das Produkt der Arbeit mir fremd ist, mir als fremde Macht gegenübertritt, wem gehört es dann? / Wenn meine eigne Tätigkeit nicht mir gehört, eine fremde, eine erzwunge Tätigkeit ist, wem gehört sie dann? / Einem andern Wesen als mir”. MEGA, I. Abteilung, Band 2, p. 669; MEW, vol. 40, p. 518.

46 Cf. Marx, Manuscritos: economía y filosofia, p. 114. 
sujeto ya no mira hacia arriba para poder recuperar su vida, sino que mira a su lado para ponerle rostro a la explotación:

El ser extraño al que pertenecen el trabajo y el producto del trabajo, a cuyo servicio está aquél y para cuyo placer sirve éste, solamente puede ser el hombre mismo. Si el producto del trabajo no pertenece al trabajador, si es frente a él un poder extraño, esto sólo es posible porque pertenece a otro hombre que no es el trabajador. Si su actividad es para él dolor, ha de ser goce y alegría vital de otro. Ni los dioses, ni la naturaleza, sino sólo el hombre mismo, puede ser este poder extraño sobre los hombres ${ }^{47}$.

Lo que se está rompiendo aquí es, en primer lugar, la posibilidad de que el trabajo, su desarrollo, pueda producir aquellos vínculos sociales de unión fraternal de la humanidad que había prometido la Aufklärung ${ }^{48}$. La libre disposición del trabajo como fuerza que produce una vida choca con el hecho de que una cierta parte de la sociedad es la dueña de los medios de producción de esa vida. La otra parte necesita de esos medios para poder trabajar. En último término, aparece aquí una relación de complementariedad que, al final, acaba por convertirse en una lucha de facciones, es decir, que aparece una relación dialéctica entendida en términos de alteridad.

Puesto que los medios de producción necesitan de la fuerza de trabajo del proletariado que los ponga en funcionamiento, la perspectiva burguesa acaba por entender la relación social en términos de necesidad mutua y de cooperación en la coexistencia. Sin embargo, Marx está afirmando aquí que sus intereses son contrapuestos, en tanto que el trabajo, que es desposeído al trabajador, no le crea más que miseria, explotación y le reduce a su animalidad. Como no se cansa de repetir a lo largo del texto, la riqueza de uno es la miseria del otro:

En el mundo práctico, real, el extrañamiento de sí solo puede manifestarse mediante la relación práctica, real, con los otros hombres. El medio mismo por el que el extrañamiento se opera es un medio práctico. En consecuencia, mediante el trabajo enajenado no sólo produce el hombre su relación con el objeto y con el acto de la propia producción como con poderes que le son extraños y hostiles, sino

47 Marx, Manuscritos: economía y filosofia, p. 114. "Das fremde Wesen, dem die Arbeit und das Produkt der Arbeit gehört, in dessen Dienst die Arbeit un zu dessen Genuss das Produkt der Arbeit steht, kann nur der Mensch selbst sein. / Wenn das Produkt der Arbeit nicht dem Arbeiter gehört, eine fremde Macht ihm gegenüber ist, so ist dies nur dadurch möglich, dass es einem andern Menschen ausser dem Arbeiter gehört. Wenn seine Tätigkeit ihm Qual ist, so muss sie einem andern Genuss und die Lebensfreude eines andern sein. Nicht die Götter, nicht die Natur, nur der Mensch selbst kann diese fremde Macht über d(en) Menschen sein". MEGA, I. Abteilung, Band 2, p. 670; MEW, vol. 40, p. 519. Marx agrega otro sentido en el que capitalista y trabajador se enfrentan: la relación de alteridad entre capitalista y obrero se establece también en torno al dinero, que hace a uno comprador y al otro vendedor de capacidad de trabajo. Cf. Marx, Ökonomische Manuskripte 1863-1867, en MEGA, II. Abteilung, Band 4, pp. 89-90.

48 Pese a que Dialektik der Aufklärung de Adorno y Horkheimer parece ser, a pesar de sus intenciones contrarias, el epitafio de la Ilustración en su conexión esencial con la explotación capitalista y el mundo que produce, no han dejado de permanecer corrientes dentro del pensamiento crítico que, todavía, no ven otra salida que volver a reivindicar los valores ilustrados como si el fin último del marxismo no fuera otra cosa que la defensa de los valores republicanos. Para un último y cercano ejemplo de esto, véase Carlos Fernández Liria y Luis Alegre Zahonero, El orden de El Capital, Akal, Madrid, 2010. 
también la relación en la que los otros hombres se encuentran con su producto y la relación en la que él está con estos otros hombres ${ }^{49}$.

La importancia de estas pocas páginas de los Manuskripte es doble. Por un lado, establece una descripción de la alteridad como un producto social; dicho de otra manera: inaugura la idea de que la alteridad no es una relación metafísica sino que está enraizada en el modo de relación social instaurado por un modo determinado de producción de riqueza. Frente a otros desarrollos más contemporáneos de la cuestión de la alteridad, en los que se tematiza la relación con algo que aparece, como puede ser el caso de Levinas ${ }^{50}$, en Marx la alteridad es una relación que se establece con un otro, cuya naturaleza depende del modo de producción de vida. El proletariado y la burguesía son dos clases sociales que se conforman en relación con la posición que cada cual ocupa en el tablero de la producción. La alteridad que constituye cada una con respecto a la otra no es más que la consecuencia de esa misma posición.

Por otro lado, Marx ya establece aquí la relación de alteridad como una relación entre enemigos. Tal y como desarrollará poco tiempo después en el Manifest, los intereses del proletariado y de la burguesía están absolutamente contrapuestos, de tal forma que cada una es enemiga para la otra ${ }^{51}$. Como ya dice en los Manuskripte, la victoria de una es la derrota de la otra. Cuando una clase se enfrenta a la otra, esta es ya un otro que se identifica como enemigo. En tanto que tal, la única relación con ella puede ser la de pretender su derrota. Esta relación solo puede entenderse como la disolución completa de aquello que determina a cada clase como enemigo, es decir, el sistema capitalista.

En definitiva, el capitalismo, al producir explotación, desposesión y extrañamiento, produce, a la vez, los grupos sociales que son necesarios para que pueda funcionar correctamente. En este proceso, no está más que creando subjetividades que dependen del mismo proceso de producción. El capitalismo produce subjetividades. Y esta forma de hacerlo es a través de una relación de alteridad basada en la lógica del enemigo ${ }^{52}$.

Por último, esta perspectiva tiene una consecuencia muy importante para el carácter anticapitalista del pensamiento emancipador contemporáneo: los continuos intentos de desactivar de formas diversas la conflictividad social, ya sea a través de la perspectiva socialdemócrata a principios del siglo veinte, o a través de la creación del Welfare State después de la Segunda Guerra Mundial, han conseguido olvidar este elemento de irreconciliabilidad que Marx presenta aquí por primera vez de forma

49 Marx, Manuscritos: economía y filosofía, p. 115. "In der praktischen wirklichen Welt kann die Selbstentfremdung nur durch das praktische, wirkliche Verhältnis zu andern Menschen erscheinen. Das Mittel, wodurch die Entfremdung vorgeht, ist selbst ein praktisches. Durch die entfremdete Arbeit erzeugt der Mensch also nicht nur sein Verhältnis zu dem Gegenstand und dem Akt der Produktion als fremden und ihm feindlichen Mächten; er erzeugt auch das Verhältnis, in welchem andre Menschen zu seiner Produktion und seinem Produkt stehn, und das Verhältnis, in welchem er zu diesen andern Menschen steht”. MEGA, I. Abteilung, Band 2, p. 671; MEW, vol. 40 , p. 519 .

50 Sobre la cuestión de la alteridad en Emmanuel Lévinas (1906-1995), su clásico Totalité et infini. Cf. Emmanuel Lévinas, Totalité et infini. Essai sur l'extériorité, Nijhoff, La Haye, 1961.

51 Véase MEW, vol. 4, Dietz Verlag, Berlin, 1977, p. 468.

52 Véase Carl Schmitt, Politische Theologie: vier Kapitel zur Lehre von der Souveränität, Duncker \& Humblot, Berlin, 1985. A pesar de las múltiples diferencias entre la concepción amigo/enemigo nazi y la que aquí ensaya Marx, lo cierto es que, a partir de los Manuksripte, podemos preguntarnos qué humanismo, si es que hay alguno, late en el fondo del proyecto de Marx, y como este estaría vacunado de las tendencias totalitarias que luego se desarrollarían en el socialismo real. 
desarrollada ${ }^{53}$ : la forma de producción de riqueza hegemónica reparte las posiciones sociales de tal forma que resulta imposible que el beneficio de una sea el beneficio de la otra. La aparición del proletariado y la burguesía implica, en este marco determinado por Marx, la concepción de la relación social en término de guerra por la supervivencia, en primer lugar, y de lucha por el control de la producción de riqueza.

Desde el punto de vista contemporáneo, todo pensamiento que quiera permanecer fiel al marxismo no tendría razones para abandonar este momento dialéctico. Ahora bien: las nuevas configuraciones sociales, en las cuales no existe sociológicamente un reparto de posiciones igual al que explica aquí Marx, hace que este principio de guerra social tenga que ser redefinido radicalmente. Esta redefinición, sin embargo, no puede desconectar el momento esencial de explotación del capitalismo de la conflictividad social. Toda estratégica política y emancipadora que implique la desactivación de este principio de guerra social puede tener la legitimidad de una victoria parcial, pero no estará atacando la base de la producción de explotación ${ }^{54}$.

Lo que es necesario conservar de este análisis es la idea de que aquí Marx está estableciendo la estructura de esa relación social basada en la explotación. La superioridad teórica que tiene este análisis consiste en que, aunque es contemporáneo de la aparición de la dialéctica proletariado/burguesía, la trasciende, puesto que explica cómo se interpretan desde un punto de vista estructural dos grupos sociales enfrentados por un cierto conjunto de relaciones sociales basadas en la explotación y la desigualdad.

En último término, esta definición de la estructura nos sirve para poder entender que, en el momento en el que el proletariado y la burguesía dejen de constituir las posiciones en las que se reparte la vida social, sería posible seguir usando este esquema de una alteridad materialista. Es posible, por lo tanto, seguir pensando en términos de conflicto social en un contexto como el contemporáneo en el que las clases sociales ya no parecen explicar las divisiones y conflictos materiales. Con el esquema de la alteridad materialista todavía es posible entender las múltiples formas de la conflictividad social contemporánea. Ahí reside la gran ventaja que supone pasar de la centralidad de la dialéctica proletariado/burguesía a la estructura de la alteridad entendida como el resultado de unas condiciones históricas de vida social basadas en la explotación y en el entendimiento recíproco en términos de enemigo.

\section{Epílogo: los Manuskripte y su papel para el pensamiento emancipador anticapitalista}

Los Manuskripte presentan un proyecto de emancipación determinado. En primer lugar, expresan las cuatro dimensiones en las que el trabajo asalariado produce el extrañamiento y la desposesión entre el mundo objetivo y aquel que lo produce: extraña el objeto que produce, la actividad misma de producir, su relación con el

53 Para un estudio de los modos en que la clase obrera ha sido integrada a través de diversas prácticas estatales de negociación, véase Erik O. Wright, Construyendo utopías reales, trad. de Ramón Cotarelo, Akal, Madrid, 2014, pp. 342-343.

54 El caso paradigmático es Podemos y su estrategia de "juego de tronos", en la cual se renuncia explícitamente a tomar como cierta la perspectiva anticapitalista. Para una exposición de la "hipótesis Podemos" en la que se abandona explícitamente el anticapitalismo por políticas neokeynesianas, véase Pablo Iglesias, "Entender Podemos" y "España en la encrucijada": New Left Review, n. 93 (2015), pp. 9-54. 
género en tanto vida universal y la relación con el otro, es decir, el extrañamiento con el resto de productores y de los dueños del capital.

Durante mucho tiempo, el papel que han desempeñado los Manuskripte en el conjunto de la obra de Marx ha servido para situar al proyecto emancipatorio que contiene en un lugar subordinado. Desde las reticencias de diverso tipo en los años posteriores a su publicación en la URSS ${ }^{55}$, así como posteriormente la enorme influencia de Althusser y su "ruptura epistemológica" en el sentido de la división estricta entre ciencia y filosofía ${ }^{56}$, todo ello ha contribuido a hacer de los Manuskripte un texto secundario con respecto a la gran obra que ha sido Das Kapital.

Desde el punto de vista estratégico y de legitimidad del marxismo, defender en nuestro presente la materialización histórica de la filosofía de Marx, el socialismo real, significa defender los elementos más regresivos no solo del materialismo histórico sino del propio Marx. Sin embargo, los Manuskripte ofrecen una salida a este problema de legitimidad. La ventaja que nos dan es que, saltando por detrás de Marx, en el sentido cronológico de ser unos textos producidos antes del total desarrollo de la crítica de la economía política, se sitúan por delante de Das Kapital y de la mayoría de elementos teórico-prácticos que han constituido el marxismo porque producen determinados conceptos con los que establecer una crítica a esas experiencias.

En definitiva, cabría hacerse la pregunta: ¿qué tipo de proyecto emancipatorio podríamos construir si en vez de Das Kapital tomáramos los Manuskripte como articulación de los elementos básicos de la transformación social? ¿Podríamos seguir llamando a esa forma de teoría-práctica "marxismo" o deberíamos buscar otro nombre al hacer referencia a elementos no solo olvidados sino rechazados por parte del marxismo histórico? ¿Podríamos seguir llamando "comunismo" a esa sociedad en la que el trabajo estuviera ya liberado de las condiciones de producción capitalistas? ¿Puede ser denominado "comunismo" al proyecto que expresa aquí Marx en la radicalidad de la relación entre trabajo, alienación y alteridad?

De cualquier modo, este nuevo proyecto, tenga el nombre que tenga, tiene que hacer frente a la cuestión del trabajo asalariado. Marx nos demuestra en los Manuskripte cómo el problema no es solo la cantidad de riqueza producida, sino el modo en el que se lleva a cabo. Los cuatro elementos desplegados en estos textos (trabajo, alienación, reducción a la animalidad y alteridad) se reducen, como el mismo Marx no deja de repetir constantemente, al trabajo como el modo en el que el sujeto produce su vida. ¿Es posible una política de la superación del trabajo asalariado? ¿Es necesaria la superación del trabajo asalariado, o las condiciones del capitalismo contemporáneo han conseguido eliminar este problema? En el caso de que fuera necesario, ¿cómo pensar en una sociedad “post-laboral”? 57.

55 Sobre la recepción de los Manuskripte en la URSS, véase Yanowitch, "Alienation and the Young Marx in Soviet Thought", pp. 29-53.

56 Véase Althusser y Balibar, Pour Marx, pp. 130 y ss.

57 Pese a que la crítica del trabajo asalariado no ha sido desarrollada en relación a la importancia que tiene desde el punto de vista de los Manuskripte, sí que ha habido buenos intentos de darle la importancia debida. Para ver varios ejemplos, véase André Gorz, Adiós al proletariado. Más allá del socialismo, trad. de Miguel Gil, El Viejo Topo, Barcelona, 2001; Kathi Weeks, The Problem with Work. Feminism, Marxism, Antiwork Politics, and Postwork Imaginaries, Duke University Press, Durham, London, 2011; Antonio Negri, Dominio y sabotaje, trad. de J. S. Grau, El Viejo Topo, Barcelona, 1979; Bob Black, La abolición del trabajo, Pepitas de calabaza, Logroño, 2013; Peter Fleming, The Mythology of Work. How Capitalism Persists Despite Itself, Pluto Press, London, 2015; Ana C. Dinerstein y Michael Neary (eds.), The Labour Debate: An Investigation into the Theory and Reality of Capitalist Work, Ashgate, Aldershot, 2002. 
Sin duda, es muy posible que enfrentarse al problema del trabajo asalariado en la forma en la que lo hace Marx aquí suponga una estrategia y un movimiento político más radical de lo que ha sido el marxismo, es decir, más capaz de ir a los problemas más profundos, a los conceptos que organizan nuestra sociedad. Es también posible que este proyecto suponga deconstruir de una forma mucho más radical los elementos principales del capitalismo contemporáneo ${ }^{58}$. Incluso, desde un punto de vista general y en relación con los diferentes modos actuales de producción de ideología, es muy posible que ya solo una verdadera política de superación del trabajo asalariado sea casi imposible de plantear.

Sin embargo, los problemas que presenta Marx en los Manuskripte no dejan de estar situados en el centro mismo de los desafíos de las sociedades occidentales contemporáneas. Por descontado, el hecho de que no puedan resolverse a primera vista no elimina la necesidad de que deban sean planteados.

\section{Referencias bibliográficas}

Adorno, Theodor y Horkheimer, Max, Dialektik der Aufklärung, Fischer Verlag, Frankfurt, 2004. Althusser, Louis y Balibar, Etienne, Pour Marx, La Découverte, Paris, 1986.

Bell, Daniel, "The Rediscovery of Alienation: Some Notes along the Quest for the Historical Marx": The Journal of Philosophy, vol. 56, n. 24 (1959), pp. 933-952.

Bitter, Sabine y Weber, Helmut (eds.), Autogestion, or Henri Lefebvre in New Belgrade, Sternberg Press, Berlin, 2009.

Black, Bob, La abolición del trabajo, Pepitas de calabaza, Logroño, 2013.

Bricianer, Serge, Pannekoek and the Workers's Councils, trad. de Malachy Carroll, Telos Press, Saint Louis, 1978.

Debord, Guy, Euvres, ed. de Jean-Louis Rançon, Gallimard, Paris, 2006.

Derrida, Jacques, The Beast \& the Soverign, vol. I, trad. de Geoffrey Bennington, The University of Chicago Press, Chicago, 2009.

-, Spectres de Marx: l'état de la dette, le travail du deuil et la nouvelle Internationale, Galilée, Paris, 1993.

Dinerstein, Ana C. y Neary, Michael (eds.), The Labour Debate: An Investigation into the Theory and Reality of Capitalist Work, Ashgate, Aldershot, 2002.

Dussel, Enrique, Hacia un Marx desconocido. Un comentario de los Manuscritos del 61-63, Siglo XXI, Ciudad de México, 1988.

Fay, Margaret A., The 1844 Economic and Philosophic Manuscripts of Karl Marx: A Critical Commentary and Interpretation, Tesis Doctoral inédita, University of California, Berkeley, 1980.

Fernández Liria, Carlos y Alegre Zahonero, Luis, El orden de El Capital, Akal, Madrid, 2010.

58 Si para la renovación del pensamiento emancipador es necesario ayudarse de algunos elementos de la tradición filosófica no exclusivamente marxista, hoy esta tarea pasa por enfrentarse, entre otras, a la deconstrucción, especialmente allí donde ha intentado establecer las conexiones entre metafísica y marxismo. Sobre deconstrucción y marxismo, véase Jacques Derrida, Spectres de Marx: l'état de la dette, le travail du deuil et la nouvelle Internationale, Galilée, Paris, 1993, pp. 21 y ss. 
Fleming, Peter, The Mythology of Work. How Capitalism Persists Despite Itself, Pluto Press, London, 2015.

Freund, Julien, "Karl Marx, un admirateur discret de Thomas Hobbes": Revue européenne des sciences sociales, t. 20, n. ${ }^{\circ} 61$ (1982), pp. 349-359.

Fukuyama, Francis, The End of History and the Last Man, Macmillan, New York, 1992.

Gorz, André, Adiós al proletariado. Más allá del socialismo, trad. de Miguel Gil, El Viejo Topo, Barcelona, 2001.

Hobbes, Thomas, Leviatán o la materia, forma y poder de un Estado eclesiástico y civil, trad. y ed. de Carlos Mellizo, Alianza, Madrid, 1999.

Iglesias, Pablo, "Entender Podemos" y "España en la encrucijada": New Left Review, n. 93 (2015), pp. 9-54.

Jameson, Fredric, Las variaciones de Hegel. Sobre la Fenomenología del espíritu, trad. de David Sánchez Usanos, Akal, Madrid, 2015.

Kohan, Néstor, Nuestro Marx, La oveja roja, Madrid, 2013.

Korsch, Karl, Marxismus und Philosophie, Europäische Verlagsanstalt, Frankfurt, 1966.

Laval, Christian y Dardot, Pierre, Común. Ensayo sobre la revolución en el siglo XXI, trad. de Alfonso Díez, Gedisa, Barcelona, 2015.

Lévinas, Emmanuel, Totalité et infini. Essai sur l'extériorité, Nijhoff, La Haye, 1961.

Marx, Karl y Engels, Friedrich, Werke (MEW), 43 vols., Dietz Verlag, Berlin, 1957-1990 (vol. 4, 1977; vol. 9, 1975; vol. 23, 1962; vol. 25, 1964; vol. 40, 1968; vol. 42, 1983).

—, Gesamtausgabe (MEGA), Dietz Verlag, Berlin, 1975-actualidad (I. Abteilung, Band 2, 2009; Ökonomische Manuskripte 1863-1867, en II. Abteilung- "Das Kapital” und Vorarbeiten, Band 4, 1988).

—, Manuscritos de París y escritos de los “Anuarios Francoalemanes” (1844), en Obras de Marx y Engels (OME), vol. 5, ed. de Manuel Sacristán Luzón y trad. de José María Ripalda, Crítica-Grijalbo, Barcelona, Buenos Aires, México, D.F., 1978.

Marx, Karl, Texte zu Methode und Praxis, II. Pariser Manuskripte 1844, ed. de Gunther Hillmann, Rowohlt, Munich, 1966.

-, Manuscritos: economía y filosofía, trad. de Francisco Rubio Llorente, Alianza, Madrid, 1979.

—, Escritos de juventud, trad. de Wenceslao Roces, Fondo de Cultura Económica, Ciudad de México, 1982.

—, Progreso técnico y desarrollo capitalista (Manuscritos 1861-1863), trad. de Raúl Crisafio y Jorge Tula, Ediciones Pasado y Presente (Siglo XXI), Ciudad de México, 1992.

- Manuscritos económico-filosóficos de 1844, trad. de Miguel Vedda, Colihue, Buenos Aires, 2004.

McInnes, Neil, "The Young Marx and the New Left": Journal of Contemporary History, vol. 6, n. 4 (1971), pp. 141-159.

Musto, Marcello, "Marx en París: Los Manuscritos económico-filosóficos de 1844”, en Marcello Musto (coord.), Tras las huellas de un fantasma. La actualidad de Marx, Siglo XXI, Ciudad de México, 2011, pp. 116-132.

Negri, Antonio, Dominio y sabotaje, trad. de J. S. Grau, El Viejo Topo, Barcelona, 1979.

—, Marx más allá de Marx. Cuaderno de trabajo sobre los Grundrisse, trad. de Carlos Prieto del Campo, Akal, Madrid, 2001.

Pannekoek, Anton, Los consejos obreros, trad. de Luis López Gutiérrez, Zero Zyx, Bilbao, 1977.

Prior Olmos, Ángel, Los Manuscritos: economía y filosofía de Karl Marx, Alianza, Madrid, 1998. 
Schmitt, Carl, Politische Theologie: vier Kapitel zur Lehre von der Souveränität, Duncker \& Humblot, Berlin, 1985.

Tedman, Gary, "Marx's 1844 Manuscripts as a work of art: A hypertextual reinterpretation": Rethinking Marxism, vol. 16, n. ${ }^{\circ}$ 4, (2004), pp. 427-441.

Veraza, Jorge, Los Manuscritos de 1844. Un discurso integral, Ítaca, México, D.F., 2011.

Weeks, Kathi, The Problem with Work. Feminism, Marxism, Antiwork Politics, and Postwork Imaginaries, Duke University Press, Durham, London, 2011.

Wright, Erik O., Construyendo utopías reales, trad. de Ramón Cotarelo, Akal, Madrid, 2014.

Yanowitch, Murray, "Alienation and the Young Marx in Soviet Thought”: Slavic Review, vol. 26, n. ${ }^{\circ} 1$ (1967), pp. 29-53.

Žižek, Slavoj (ed.), La idea de comunismo. The New York Conference (2011), trad. de Juan Gorostidi Mungia y Francisco López Martín, Akal, Madrid, 2014.

-, Absolute Recoil: Towards a New Foundation of Dialectical Materialism, Verso, London, New York, 2015. 